\title{
Cellular Metals: Fabrication, Properties and Applications
}

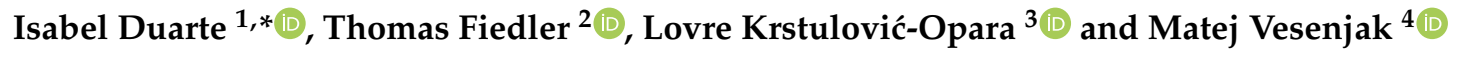 \\ 1 Center for Mechanical Technology and Automation, Department of Mechanical Engineering, \\ University of Aveiro Campus Universitário de Santiago, 3810-193 Aveiro, Portugal \\ 2 Centre for Mass and Thermal Transport in Engineering Materials, School of Engineering, \\ The University of Newcastle, Callaghan NSW 2308, Australia; thomas.fiedler@newcastle.edu.au \\ 3 Faculty of Electrical Engineering, Mechanical Engineering and Naval Architecture, University of Split, \\ 21000 Split, Croatia; Lovre.Krstulovic-Opara@fesb.hr \\ 4 Faculty of Mechanical Engineering, University of Maribor, 2000 Maribor, Slovenia; matej.vesenjak@um.si \\ * Correspondence: isabel.duarte@ua.pt
}

Received: 2 November 2020; Accepted: 17 November 2020; Published: 20 November 2020

\section{Introduction and Scope}

Cellular solids and porous metals have become some of the most promising lightweight multifunctional materials due to their superior combination of advanced properties mainly derived from their base material and cellular structure. They are used in a wide range of commercial, biomedical, industrial, and military applications. In contrast to other cellular materials, cellular metals are non-flammable, recyclable, extremely tough, and chemically stable and are excellent energy absorbers. The manuscripts of this Special Issue provide a representative insight into the recent developments in this field, covering topics related to manufacturing, characterization, properties, specific challenges in transportation, and the description of structural features. For example, a presented strategy for the strengthening of Al-alloy foams is the addition of alloying elements (e.g., magnesium) into the metal bulk matrix to promote the formation of intermetallics (e.g., precipitation hardening). The incorporation of micro-sized and nano-sized reinforcement elements (e.g., carbon nanotubes and graphene oxide) into the metal bulk matrix to enhance the performance of the ductile metal is presented. New bioinspired cellular materials, such as nanocomposite foams, lattice materials, and hybrid foams and structures are also discussed (e.g., filled hollow structures, metal-polymer hybrid cellular structures).

\section{Contributions}

Sixteen original scientific contributions (fifteen original articles and one review paper) on different topics of cellular metals have been published in this Special Issue. Seven contributions focus on the advances in production and manufacturing technologies for aluminum alloy foams and the understanding of the foaming behavior and the fundamental relationships between their structure and their properties, with some even exploring nano-sized reinforcement elements. García-Moreno et al. [1] investigate the influence of the alloy composition and the role of the liquid phase and its influence on the gas nucleation and foaming of $\mathrm{Al}-\mathrm{Si}-\mathrm{Mg}$ alloys prepared by the powder metallurgy method using in-situ $\mathrm{X}$-ray radioscopy, $\mathrm{X}$-ray tomography, and X-ray tomoscopy. Lehmhus et al. [2] analyze the effects of the solidification rates and addition of $\mathrm{Sr}, \mathrm{B}$, and TiB2/TiAl3 on the foaming behavior and microstructural, morphological, and mechanical properties of aluminum foams fabricated by the powder metallurgy method. Duarte et al. [3] present an automated production line composed of a continuous furnace, a cooling sector, and a robotic system to fabricate metal foam parts and/or components using a powder metallurgical method. Several case studies are also provided. Three original contributions from Kuwahara et al. [4-6] related to direct foaming methods, as an alternative to the powder metallurgy 
method, are also presented. In the first contribution, Kuwahara et al. [4] investigate the pore formation of $\mathrm{Al}-\mathrm{Cu}-\mathrm{Mg}$ foams fabricated by the melt route using magnesium as a thickening agent or by the semi-solid route using primary crystals at a semi-solid temperature with a solid fraction of $20 \%$. They analyze the nano-sized and micro-sized precipitates of the cell wall and the effect of the cell wall structure and pore morphology on the compressive properties. Kuwahara et al. [5] characterize the compressive properties of $\mathrm{Al}-\mathrm{Cu}-\mathrm{Mg}$ foam fabricated by the melt route and the semi-solid route. They also provide a morphological, microstructural, and metallurgical analysis. Kuwahara et al. [6] analyze and numerically evaluate the stabilization mechanism of the cell walls of the aluminum alloy foams prepared by a semi-solid route in which the melt is thickened by primary crystals. Trejo-Rivera et al. [7] present a methodology based on a direct foaming method to fabricate aluminum alloy foams made of A-242 alloy from the recycling of secondary aluminum obtained from beverage cans, using calcium and titanium hydride as a thickening and blowing agent, respectively. They provide microstructural and metallurgical analyses and the mechanical properties. Three contributions discuss the reinforcing role of carbon nanostructures (e.g., multiwalled carbon nanotubes and graphene oxide) in developing new cellular structures with enhanced properties. Damanik and Lange [8] investigate the effect of multiwalled carbon nanotubes coated with nickel on the foaming behavior and morphology of reinforced $\mathrm{AlMg} 4 \mathrm{Si} 8$ foam prepared by a powder metallurgy process. Pinto et al. [9,10] present novel aluminum foam-polymer nanocomposite hybrid structures, providing the structural, mechanical, thermal, and acoustic properties. These hybrid structures are prepared by infiltrating an open-cell aluminum foam with a polymer (epoxy [9] and polyurethane foams [10] with or without graphene oxide) to enhance the performance of the resulting hybrid structures. The three following contributions are focused on new cellular structures to be applied for structural applications. Vesenjak et al. [11] present a novel approach to fabricate aluminum unidirectional cellular structures with longitudinal pores by rolling a thin aluminum foil with acrylic spacers and finally compacting by explosion welding. They provide the metallographic, quasi-static, and dynamic compressive properties. The fabrication process and influencing parameters have been further studied using computational simulations. Yang et al. [12] present a comparative numerical study of the uniaxial behavior of three lattice materials-face center cube, edge center cube, and vertex cube-generated using topology optimization and crystal inspiration. They provide a characterization of their deformation modes, mechanical properties, and energy absorption capabilities. Xu et al. [13] analytically and numerically describe the elasto-plastic behavior of transversely isotropic cellular materials with inner gas pressure, focusing on a gas-filled ellipsoidal-cell face center cube foam with a relative density of 0.5. Yang et al. [14] report the findings of an experimental and numerical work developed to study the sound absorption performance of 10-layer gradient compressed porous metal to be applied for noise reduction. Hangai et al. [15] introduce a new manufacturing method to fabricate steel tubes filled with aluminum foam from aluminum burrs of die-castings by friction stir back extrusion. They further determine the compressive behavior and potential applications for impact energy absorption. Finally, Duarte et al. [16] present a brief review of the main experimental and numerical techniques and standards to investigate and quantify the structural, mechanical, thermal, and acoustic properties of cellular metals.

\section{Conclusions and Outlook}

The contributions of this Special Issue present recent advances in cellular metal research. Cellular metals enable an immediate weight reduction and material saving of components. Simultaneously, they can perform multiple functions due to their three-dimensional cellular structures. Despite these advantages, the commercial use of cellular metals is still limited due to the high production costs required to create regular cellular structures (topology and morphology). Another inhibitor to their application is the random variation in their mechanical, acoustic, and thermal behavior. However, new technical solutions ensure that these materials can be produced in a commercially profitable way 
with the required quality and reproducibility, such that their integration into engineering structures can fully utilize their unique properties.

Acknowledgments: The guest editors would like to thank all the authors for their contributions and the reviewers for their outstanding efforts to improve the scientific quality of the different contributions. We would also like to thank the staff at the Metals Editorial Office, particularly Betty Jin, who supported and managed the publication process.

Conflicts of Interest: The authors declare no conflict of interest.

\section{References}

1. García-Moreno, F.; Radtke, L.A.; Neu, T.R.; Kamm, P.H.; Klaus, M.; Schlepütz, C.M.; Banhart, J. The Influence of Alloy Composition and Liquid Phase on Foaming of Al-Si-Mg Alloys. Metals 2020, 10, 189. [CrossRef]

2. Lehmhus, D.; Hünert, D.; Mosler, U.; Martin, U.; Weise, J. Effects of Eutectic Modification and Grain Refinement on Microstructure and Properties of PM AlSi7 Metallic Foams. Metals 2019, 9, 1241. [CrossRef]

3. Duarte, I.; Vesenjak, M.; Vide, M.J. Automated Continuous Production Line of Parts Made of Metallic Foams. Metals 2019, 9, 531. [CrossRef]

4. Kuwahara, T.; Saito, M.; Osaka, T.; Suzuki, S. Effect of Primary Crystals on Pore Morphology during Semi-Solid Foaming of A2024 Alloys. Metals 2019, 9, 88. [CrossRef]

5. Kuwahara, T.; Osaka, T.; Saito, M.; Suzuki, S. Compressive Properties of A2024 Alloy Foam Fabricated through a Melt Route and a Semi-Solid Route. Metals 2019, 9, 153. [CrossRef]

6. Kuwahara, T.; Kaya, A.; Osaka, T.; Takamatsu, S.; Suzuki, S. Stabilization Mechanism of Semi-Solid Film Simulating the Cell Wall during Fabrication of Aluminum Foam. Metals 2020, 10, 333. [CrossRef]

7. Trejo-Rivera, N.M.; Torres Torres, J.; Flores Valdés, A. A-242 Aluminium Alloy Foams Manufacture from the Recycling of Beverage Cans. Metals 2019, 9, 92. [CrossRef]

8. Damanik, F.S.; Lange, G. Influence of MWCNT Coated Nickel on the Foaming Behavior of MWCNT Coated Nickel Reinforced AlMg4Si8 Foam by Powder Metallurgy Process. Metals 2020, 10, 955. [CrossRef]

9. Pinto, S.C.; Marques, P.A.; Vesenjak, M.; Vicente, R.; Godinho, L.; Krstulović-Opara, L.; Duarte, I. Mechanical, Thermal, and Acoustic Properties of Aluminum Foams Impregnated with Epoxy/Graphene Oxide Nanocomposites. Metals 2019, 9, 1214. [CrossRef]

10. Pinto, S.C.; Marques, P.A.A.P.; Vicente, R.; Godinho, L.; Duarte, I. Hybrid Structures Made of Polyurethane/Graphene Nanocomposite Foams Embedded within Aluminum Open-Cell Foam. Metals 2020, 10, 768. [CrossRef]

11. Vesenjak, M.; Nishi, M.; Nishi, T.; Marumo, Y.; Krstulović-Opara, L.; Ren, Z.; Hokamoto, K. Fabrication and Mechanical Properties of Rolled Aluminium Unidirectional Cellular Structure. Metals 2020, 10, 770. [CrossRef]

12. Yang, C.; Xu, K.; Xie, S. Comparative Study on the Uniaxial Behaviour of Topology-Optimised and Crystal-Inspired Lattice Materials. Metals 2020, 10, 491. [CrossRef]

13. Xu, Z.; Meng, K.; Yang, C.; Zhang, W.; Fan, X.; Sun, Y. Elasto-Plastic Behaviour of Transversely Isotropic Cellular Materials with Inner Gas Pressure. Metals 2019, 9, 901. [CrossRef]

14. Yang, F.; Shen, X.; Bai, P.; Zhang, X.; Li, Z.; Yin, Q. Optimization and Validation of Sound Absorption Performance of 10-Layer Gradient Compressed Porous Metal. Metals 2019, 9, 588. [CrossRef]

15. Hangai, Y.; Kobayashi, R.; Suzuki, R.; Matsubara, M.; Yoshikawa, N. Aluminum Foam-Filled Steel Tube Fabricated from Aluminum Burrs of Die-Castings by Friction Stir Back Extrusion. Metals 2019, 9, 124. [CrossRef]

16. Duarte, I.; Fiedler, T.; Krstulović-Opara, L.; Vesenjak, M. Brief Review on Experimental and Computational Techniques for Characterization of Cellular Metals. Metals 2020, 10, 726. [CrossRef]

Publisher's Note: MDPI stays neutral with regard to jurisdictional claims in published maps and institutional affiliations.

(C) 2020 by the authors. Licensee MDPI, Basel, Switzerland. This article is an open access article distributed under the terms and conditions of the Creative Commons Attribution (CC BY) license (http://creativecommons.org/licenses/by/4.0/). 